\title{
p-Xylene catalytic oxidation to terephthalic acid by ozone
}

\author{
Helin Pan*, Shuting Li, Mingjie Shu, Yuwei Ye, Qiuhua Cui, Zhixiang Zhao \\ School of Chemical Engineering, East China University of Science and Technology, Shanghai 200237 China
}

*Corresponding author, e-mail: panhl@ecust.edu.cn

Received 20 Mar 2018

Accepted 17 May 2018

\begin{abstract}
The process of $p$-xylene (PX) catalytic oxidation to terephthalic acid (TA) was studied at $60-110^{\circ} \mathrm{C}$ and atmospheric pressure with cobalt acetate as catalyst, glacial acetic acid as solvent, and ozone-containing air as oxidant. Effects of catalyst, temperature, ozone concentration, reaction time, and bromide on PX conversion and product selectivity were investigated. Results showed that PX was oxidized with $76 \%$ conversion and $84 \%$ selectivity for TA at $80^{\circ} \mathrm{C}$ under $63.0 \mathrm{mg} / 1$ ozone concentration for $6 \mathrm{~h}$ at $0.8 \mathrm{l} / \mathrm{min}$ gas flow rate when the mole ratio of PX to cobalt acetate was 10:1. PX conversion and TA selectivity could reach $96 \%$ and $84 \%$ when the mole ratio of $\mathrm{PX}$ to $\mathrm{KBr}$ was 1.84:1. When cobalt acetate, ozone, and bromide were simultaneously used, an obvious synergistic effect on the PX oxidation reaction was noted. Increasing the temperature gradually weakened the effect because the decomposition rate of ozone was accelerated.
\end{abstract}

KEYWORDS: cobalt acetate, Co-Br catalyst, reaction mechanism, process optimization

\section{INTRODUCTION}

Terephthalic acid (TA) is an important material in polyester production ${ }^{1}$. At present, the most representative production method of TA is the liquid air oxidation method, which uses $p$-xylene (PX) as a raw material, cobalt-manganese-bromine as a catalytic system, and acetic acid as a solvent ${ }^{2}$. The reaction requires high temperature and pressure, harsh conditions, and the presence of bromide ions could cause severe corrosion. High temperatures would reduce the selectivity of the reaction while the decarboxylation of $\mathrm{Co}^{3+}$ and the combustion reaction of the solvent aggravate ${ }^{3}$. Up until now, the oxidation reaction mostly uses molecular oxygen or air as the oxidant and there has been few reports of studies on the new oxidant. Hence this paper proposed a new process, which was under the conditions of low temperature, atmospheric pressure, cobalt acetate as a catalyst, and ozone-containing air as a new oxidant (under acidic conditions, with the ozone standard oxidation-reduction potential of $2.07 \mathrm{~V}$ ) and then TA was prepared by catalytic oxidation of PX in a homogeneous system. In this study, the simplified reaction mechanism of PX oxidation is shown in Fig. 1. The reaction and the kinetic constants of bromine with ozone are shown in Fig. 2. Studies have shown that the lower the $\mathrm{pH}$, the less $\mathrm{BrO}_{3}^{-}$formed. In this experiment, acetic acid is used as a solvent and the $\mathrm{pH}$ value is low, so the action of ozone bromine ions mainly produced $\mathrm{HBrO}^{4}$. The circulating diagram of Co-Br catalytic mechanism is shown in Fig. 3.

\section{EXPERIMENTAL}

\section{Materials}

The main reagents were as follows: $p$-xylene, acetonitrile (chromatographically pure), glacial acetic acid, cobalt acetate (Jiangsu Zhengdan Chemical Industry Co., Ltd.), KBr, dimethyl sulphoxide, terephthalic acid, $p$-toluic acid, and phosphoric acid (the unlabelled reagents are all analytically pure).

\section{Apparatus}

Four-necked flask (500 ml), BSA224S analytical balance, ACO-318air pump, JJ-1 electric mixer, SHBIII vacuum pump, SZCL-2 digital thermowell, DZF6050 vacuum drying Box, L1260 high performance liquid chromatography, Xinsong oxygen molecular sieve, and ozone generator (Qingdao Guolin Environmental Protection Technology Co., Ltd., 10 g/h).

\section{Experimental approach}

A certain amount of substance $p$-xylene, $0.10 \mathrm{~mol} /$ mol PX of cobalt acetate catalyst and $17.5 \mathrm{~mol} /$ mol PX of glacial acetic acid were added to a fournecked flask, and the mixture was heated to the specified temperature at atmospheric pressure with stirring. After separating some of the nitrogen in 


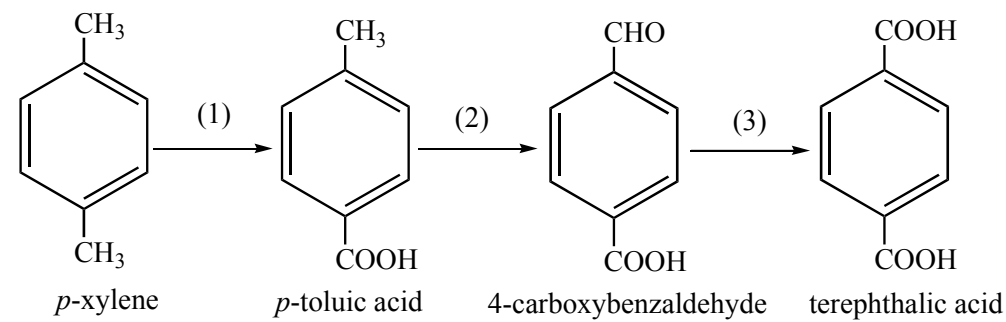

Fig. 1 Simplified reaction mechanism of PX oxidation.

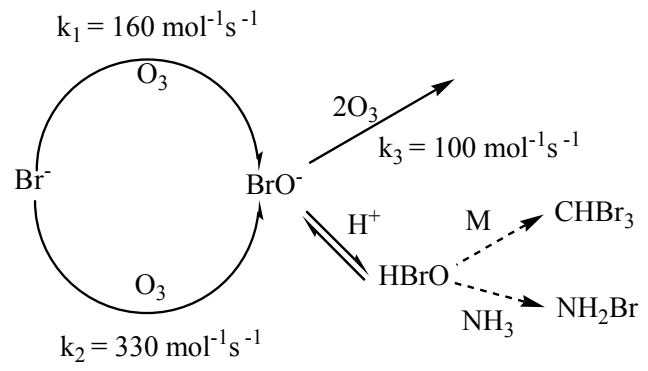

Fig. 2 Oxidation reaction of $\mathrm{Br}^{-}$and $\mathrm{O}_{3}$.

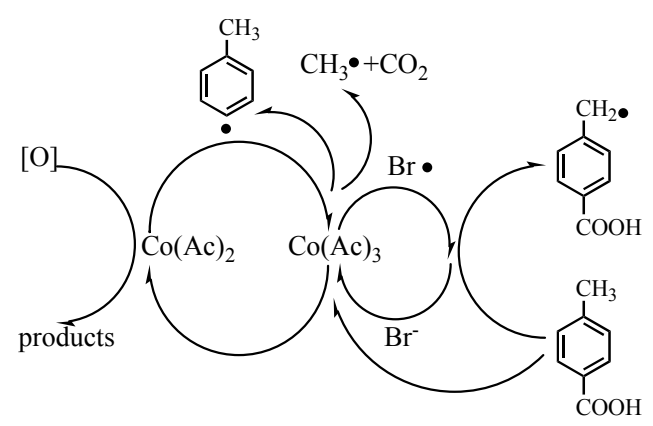

Fig. 3 Circulating diagram of Co-Br catalytic mechanism.

the air through the air separator and measuring the oxygen-enriched air through the gas flow meter, the ozone-containing air can be prepared by the ozone generator (air source) and adjusted to a specific ozone concentration. When the reaction system rose to the specified temperature, the ozonecontaining air began to flow in and the reaction started to count. After the reaction was completed, the solid-liquid sample was separated by filtration after cooling to room temperature, and the product was analysed by L1260 high performance liquid chromatography.

\section{Analytical method}

Solid-liquid products were analysed by L1260 high performance liquid chromatography (Agilent Technologies); column, Agilent 5 TC-C18 (2)
$250 \times 4.6 \mathrm{~mm}$; mobile phase, acetonitrile/water $(\mathrm{V}: \mathrm{V}=4: 6)$, the $\mathrm{pH}$ of the aqueous phase was adjusted to 3.7-3.8 with phosphoric acid; flow rate $1 \mathrm{ml} / \mathrm{min}$; VWD detector; chromatographic column temperature $35^{\circ} \mathrm{C}$; detection wavelength $240 \mathrm{~nm}$; injection volume $5 \mu \mathrm{l}$. The characteristics of the sample analysed using this method are fast and accurate $^{5}$. The time to completion of an analysis was less than $12 \mathrm{~min}$.

\section{RESULTS AND DISCUSSION}

\section{Different catalyst effects}

Under the conditions of catalyst dosage $0.10 \mathrm{~mol} /$ mol PX, $\mathrm{KBr}$ dosage $0.545 \mathrm{mmol} / \mathrm{mol} \mathrm{PX}$, reaction temperature $110^{\circ} \mathrm{C}$, reaction time $6 \mathrm{~h}$, ozone concentration $15.0 \mathrm{mg} / \mathrm{l}$, and gas flow rate $0.8 \mathrm{l} / \mathrm{min}$. There are a variety of intermediate oxidation products ${ }^{6,7} p$-toluyl alcohol (TALC), $p$-tolualdehyde (TALD), $p$-toluic acid (PT), terephthalaldehyde, and p-carboxybenzaldehyde (4-CBA), etc. In this study, the total selectivity of TA, PT, and 4-CBA was basically above $95 \%$, and the selectivity of other byproducts was very low. Hence the selectivity of these three products was mainly studied. The effects of different catalysts on the conversion rate of PX and the selectivity of the main products were investigated and the results presented in Table 1.

As can be seen from Table 1, when cobalt chloride hexahydrate or cobalt acetate tetrahydrate was used as catalyst, the conversion of PX was relatively low, corresponding to $51 \%$ and $70 \%$, respectively.

Table 1 Oxidation effect of $p$-xylene using different catalyst.

\begin{tabular}{lcccc}
\hline Catalyst & \multirow{2}{*}{$\begin{array}{c}\text { PX rate } \\
\text { (per \%) }\end{array}$} & \multicolumn{3}{c}{ Selectivity (per \%) } \\
\cline { 3 - 5 } & & TA & 4-CBA & PT \\
\hline $\begin{array}{l}\text { Cobalt chloride } \\
\text { hexahydrate }\end{array}$ & $50.6 \pm 0.2$ & $73.6 \pm 0.2$ & $16.2 \pm 0.2$ & $5.8 \pm 0.1$ \\
$\begin{array}{l}\text { Cobalt acetate } \\
\text { tetrahydrate }\end{array}$ & $69.8 \pm 0.1$ & $82.9 \pm 0.2$ & $7.4 \pm 0.1$ & $3.2 \pm 0.1$ \\
Cobalt acetate & $97.0 \pm 0.2$ & $81.9 \pm 0.1$ & $9.5 \pm 0.1$ & $3.8 \pm 0.1$ \\
\hline
\end{tabular}




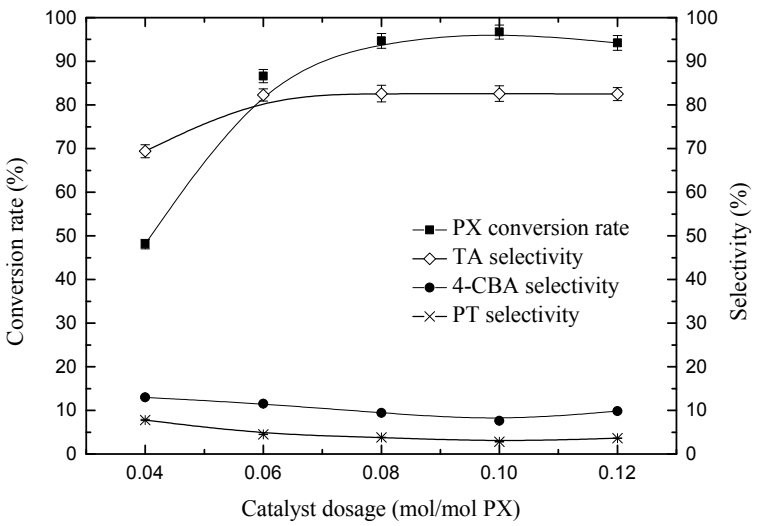

Fig. 4 Effect of catalyst dosage on $p$-xylene oxidation.

However, when cobalt acetate was used as catalyst, the conversion reached up to $97 \%$ and TA selectivity increased to $82 \%$ accordingly. This showed that this reaction needed to be carried out in an anhydrous environment. Both cobalt chloride hexahydrate and cobalt acetate tetrahydrate could introduce water, which would result in reducing catalytic performance. Hence this work chose cobalt acetate as a catalyst.

\section{Catalyst dosage investigation}

Fig. 4 showed the effect of catalyst cobalt acetate dosage on PX conversion rate and the selectivity of the main products. The reaction conditions were as follows: the reaction temperature was $110^{\circ} \mathrm{C}$, the reaction time was $6 \mathrm{~h}$, the dosage of $\mathrm{KBr}$ was $0.545 \mathrm{mmol} / \mathrm{mol} \mathrm{PX}$, the ozone concentration was $12.0 \mathrm{mg} / \mathrm{l}$, and the gas flow rate was $0.8 \mathrm{l} / \mathrm{min}$.

As can be seen from Fig. 4, with the dosage of catalyst cobalt acetate increased, PX conversion rate kept rising at first, reaching a maximum of $97 \%$ at $0.10 \mathrm{~mol} / \mathrm{mol} \mathrm{PX}$, and then decreased slightly; and TA selectivity increased. When the dosage was greater than $0.08 \mathrm{~mol} / \mathrm{mol} \mathrm{PX}$, TA selectivity tended to be stable at $83 \%$; the selectivity of both 4-carboxybenzaldehyde (4-CBA) and p-toluic acid (PT) dropped at first, falling to the bottom of $8 \%$ and $3 \%$ at $0.10 \mathrm{~mol} / \mathrm{mol} \mathrm{PX}$, respectively, and then showed a trend of recovery.

This was because the strong oxidizability of $\mathrm{Co}^{3+}$ initiated the radical reaction in the glacial acetic acid solvent and the redox potential was as high as $1.9 \mathrm{~V}^{8}$. Increasing the dosage of cobalt acetate was conducive to increasing the concentration of $\mathrm{Co}^{3+}$ and promoting the conversion of methyl group in PX to the aldehyde group and the carboxyl group. However, the excess catalyst did not have a

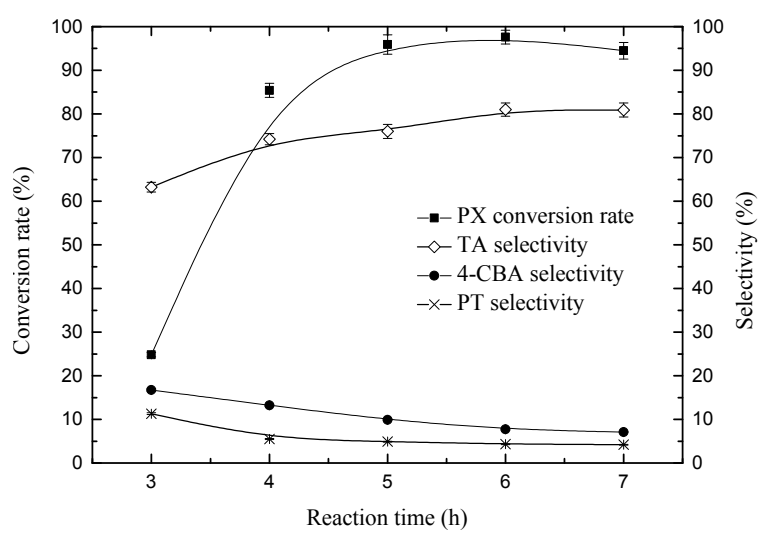

Fig. 5 Effect of reaction time on $p$-xylene oxidation.

stronger promoting effect on the reaction. For the least amount of impurities, such as 4-CBA and PT in TA, the dosage of catalyst should be controlled at $0.10 \mathrm{~mol} / \mathrm{mol} \mathrm{PX}$.

\section{Effect of reaction time}

Under the conditions of catalyst dosage $0.10 \mathrm{~mol} /$ mol PX, $\mathrm{KBr}$ dosage $0.545 \mathrm{mmol} / \mathrm{mol} \mathrm{PX}$, reaction temperature $110^{\circ} \mathrm{C}$, reaction time $6 \mathrm{~h}$, ozone concentration $20.0 \mathrm{mg} / \mathrm{l}$ and gas flow rate $0.8 \mathrm{l} / \mathrm{min}$, the effect of reaction time on the conversion rate of PX and the selectivity of the main products were investigated in Fig. 5.

As can be seen from Fig. 5, with the extension of the reaction time, the PX conversion rate first sharply increased, reaching a maximum of $98 \%$ at $6 \mathrm{~h}$, and then decreased slightly; the selectivity of TA increased steadily first and then stabilized at $81 \%$ after $6 \mathrm{~h}$. The selectivity of 4-CBA and PT were steadied at around $7 \%$ and $4 \%$, respectively. The reaction was free radical reaction and took place quickly after the initiation period, representing as the rapid increase in PX conversion rate and the selectivity of the product phthalic acid, as well as the decrease in by-products selectivity. However, with the prolongation of the reaction time, trace amount of phenols might form in the by-products ${ }^{9}$, leading to the termination of the free-radical chain reaction and the reduction of PX yield. Hence the optimum reaction time was $6 \mathrm{~h}$.

\section{Effect of ozone concentration}

Under the conditions of catalyst dosage $0.10 \mathrm{~mol} /$ mol PX, reaction temperature $110^{\circ} \mathrm{C}$, reaction time $6 \mathrm{~h}$, and gas flow rate $0.8 \mathrm{l} / \mathrm{min}$, the effect of ozone concentration on the conversion rate of PX and the 


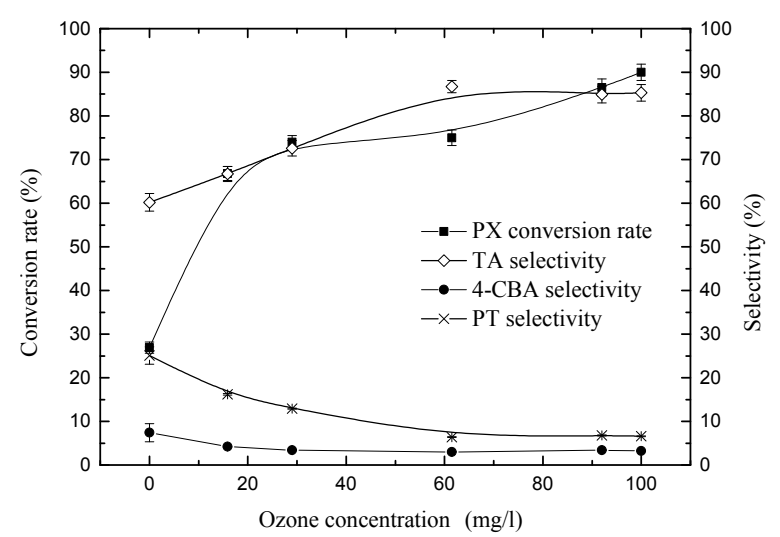

Fig. 6 Effect of ozone concentration on p-xylene oxidation.

selectivity of the main products without bromide were investigated in Fig. 6.

As can be seen from Fig. 6, when the other conditions remained unchanged, with ozone concentration of $0-30 \mathrm{mg} / \mathrm{l}$, PX conversion rate and selectivity of TA increased significantly, selectivity of 4-CBA and PT decreased significantly. This was because the presence of ozone could not only directly promote the oxidation of methyl groups in PX to aldehydes and carboxyl groups ${ }^{10}$, but also accelerate the conversion of $\mathrm{Co}^{2+}$ to $\mathrm{Co}^{3+}$ in the system to shorten the chain initiation time and speed up the oxidation reaction. When the ozone concentration was between 30 and $63 \mathrm{mg} / \mathrm{l}$, the conversion of PX and the selectivity of TA continued to increase steadily to a moderate extent; the selectivity of PT decreased continuously, while the selectivity of 4-CBA remained constant at about $3 \%$. When the ozone concentration was between 63 and $100 \mathrm{mg} / \mathrm{l}$, the selectivities of TA, 4-CBA and PT were basically stable, respectively, at $85 \%, 3 \%$, and $7 \%$ while PX conversion rate showed a sharp uptrend. This phenomenon could be attributed to the high concentration of ozone which not only improved the reaction rate to accelerate PX conversion process, but also was more conducive to the conversion of methyl to aldehyde, and carboxyl in PT, as shown in the reaction process step (2) and (3) of Fig. 1.

This indicated that both low concentrations and high concentrations of ozone could significantly improve the conversion of PX and promote the reaction.

\section{Effect of reaction temperature}

Under the conditions of catalyst dosage $0.10 \mathrm{~mol} /$ mol PX, $\mathrm{KBr}$ dosage $0.545 \mathrm{mmol} / \mathrm{mol} \mathrm{PX}$, reaction

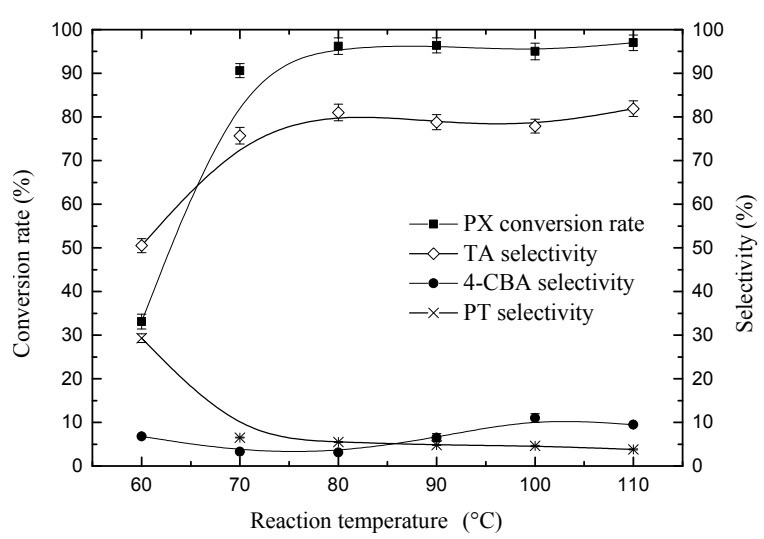

Fig. 7 Effect of reaction temperature on $p$-xylene oxidation.

time $6 \mathrm{~h}$, ozone concentration $20.0 \mathrm{mg} / \mathrm{l}$, and gas flow rate $0.8 \mathrm{l} / \mathrm{min}$, the effect of reaction temperature on the conversion rate of PX and the selectivity of the main products were investigated in Fig. 7.

As can be seen from Fig. 7, when the reaction temperature was in the range of $60-80^{\circ} \mathrm{C}$, the $\mathrm{PX}$ conversion rate and TA selectivity sharply increased, and the selectivity of 4-CBA and PT continuously decreased, indicating that low temperature was conducive to PX to TA conversion.

When the reaction temperature was within the range of $80-110^{\circ} \mathrm{C}$, the conversion of $\mathrm{PX}$ and selectivity of PT were basically stable at $96 \%$ and $5 \%$, respectively, while the selectivity of TA decreased first and then increased, 4-CBA selectivity increased first and then decreased, but the magnitude did not change much.

This was because the accelerated ozone decomposition decreased ozone concentration and gradually decreased oxidation within the range of 80 $100^{\circ} \mathrm{C}$. It was not conducive to the carboxyl group in the intermediate product, 4-CBA, into aldehyde to generate TA; on the other hand, the increased temperature was more conducive to the decarboxylation reaction, resulting in the selectivity of 4-CBA. When the reaction temperature was higher than $100^{\circ} \mathrm{C}$, the low concentration of ozone had little effect on the reaction. In this case, heating contributed to the oxidation of aldehydes groups to carboxyl groups, then the selectivity of 4-CBA decreased and the selectivity of TA increased.

\section{Effects of different factors at $80^{\circ} \mathrm{C}$}

Under the conditions of catalyst dosage $0.10 \mathrm{~mol} /$ mol PX, KBr dosage $0.545 \mathrm{mmol} / \mathrm{mol} \mathrm{PX}$, reaction temperature $80^{\circ} \mathrm{C}$, reaction time $6 \mathrm{~h}$, ozone con- 
Table 2 Effect of different factors on $p$-xylene oxidation at $80^{\circ} \mathrm{C}$.

\begin{tabular}{llllllrr}
\hline No. & Catalyst & $\mathrm{O}_{3}$ & $\mathrm{KBr}$ & \multirow{2}{*}{$\begin{array}{l}\text { PX rate } \\
\text { (per \%) }\end{array}$} & \multicolumn{3}{c}{ Selectivity (per \%) } \\
\cline { 6 - 8 } & & & & & TA & 4-CBA & PT \\
\hline 1 & No & Yes & No & $4.8 \pm 0.03$ & $73.5 \pm 0.13$ & $3.0 \pm 0.05$ & $16.8 \pm 0.08$ \\
2 & Yes & No & No & $34.7 \pm 0.09$ & $67.4 \pm 0.09$ & $4.3 \pm 0.03$ & $20.9 \pm 0.11$ \\
3 & Yes & Yes & No & $71.9 \pm 0.15$ & $86.7 \pm 0.16$ & $3.0 \pm 0.03$ & $6.4 \pm 0.04$ \\
4 & Yes & Yes & Yes & $95.0 \pm 0.17$ & $84.3 \pm 0.15$ & $3.1 \pm 0.02$ & $5.6 \pm 0.07$ \\
\hline
\end{tabular}

Table 3 Effect of different factors on $p$-xylene oxidation at $110^{\circ} \mathrm{C}$.

\begin{tabular}{lcccccrr}
\hline No. & Perchlorethylene & $\mathrm{O}_{3}$ & $\mathrm{KBr}$ & \multirow{2}{*}{$\begin{array}{l}\text { PX rate } \\
\text { (per \%) }\end{array}$} & \multicolumn{3}{c}{ Selectivity (per \%) } \\
\cline { 6 - 8 } & & & & & \multicolumn{1}{c}{ 4-CBA } & PT \\
\hline 5 & Yes & No & Yes & $95.9 \pm 0.21$ & $79.0 \pm 0.20$ & $10.0 \pm 0.12$ & $4.2 \pm 0.06$ \\
6 & No & Yes & Yes & $96.8 \pm 0.19$ & $79.6 \pm 0.18$ & $3.6 \pm 0.05$ & $4.1 \pm 0.06$ \\
7 & Yes & Yes & No & $26.0 \pm 0.08$ & $74.5 \pm 0.19$ & $5.0 \pm 0.06$ & $13.1 \pm 0.11$ \\
8 & Yes & Yes & Yes & $97.1 \pm 0.08$ & $81.9 \pm 0.09$ & $9.5 \pm 0.09$ & $3.8 \pm 0.05$ \\
\hline
\end{tabular}

centration $58.7 \mathrm{mg} / \mathrm{l}$, and gas flow rate $0.8 \mathrm{l} / \mathrm{min}$, the effects of the interaction of ozone, bromide and catalyst on the PX conversion rate and the selectivity of the main products were investigated. The results were shown in Table 2.

From the experimental data in groups 1 and 2 , it can be seen that PX conversion rate and TA selectivity were low while PT selectivity was high when the ozone and the catalyst acted alone on the reaction. This indicated that when only ozone or cobalt acetate was used, the two methyl groups of xylene could be directly oxidized to the aldehyde group and the carboxyl group, but the oxidation reaction rate of each step was slower. It had been shown ${ }^{7,11}$ that the oxidation of the second methyl group on the benzene ring was far more difficult than the oxidation of the first methyl group on cobalt as the catalyst alone. The data suggested that the cobalt catalytic activity of the second methyl group was less than $1 / 42$ of the cobalt catalytic activity of the first methyl group, which resulted in extremely slow the oxidation of the second methyl group (less than $1 / 27$ of the PX oxidation rate).

From groups 1,2 , and 3 , it can be seen that when the catalyst cobalt acetate and ozone were used simultaneously, PX conversion and TA selectivity could be remarkably increased while the selectivity of PT can be remarkably reduced. This showed that cobalt and ozone had significant synergistic effect, which could significantly improve the oxidation reaction rate, especially for the oxidation rate of PT in step (2) of the reaction process with effectively increased the oxidation degree.

From groups $1,2,3$, and 4 , it can be seen that the conversion of $p$-xylene could be further boosted up to $95 \%$ when the cobalt acetate, ozone, and $\mathrm{KBr}$ played a role in the reaction at the same time. This demonstrated that cobalt acetate, ozone, and bromides used simultaneously had a stronger synergistic effect, the introduction of bromine could significantly improve PX conversion rate. Studies ${ }^{12}$ had shown that $\mathrm{Co}^{3+}$ ions were easily decarboxylated with acetic acid solvent; with the introduction of bromine, on the one hand, it could reduce the concentration of $\mathrm{Co}^{3+}$ to inhibit the decarboxylation, on the other hand, it provided many highly active and highly selective bromine radicals, so as to accelerate the progress of the reaction.

\section{Effects of different factors at $110^{\circ} \mathrm{C}$}

Under the conditions of catalyst dosage $0.10 \mathrm{~mol} /$ $\mathrm{mol} \mathrm{PX,} \mathrm{KBr}$ dosage $0.545 \mathrm{mmol} / \mathrm{mol} \mathrm{PX}$, reaction temperature $110^{\circ} \mathrm{C}$, reaction time $6 \mathrm{~h}$, ozone concentration $20.0 \mathrm{mg} / \mathrm{l}$, gas flow rate $0.8 \mathrm{l} / \mathrm{min}$, and perchlorethylene $1 \mathrm{ml}$, the effects of the interaction of ozone, bromide, and perchlorethylene (accelerator) on the PX conversion rate and the selectivity of the main products were investigated. The results were shown in Table 3.

From groups 5 and 8 , it can be seen that the effect of low concentrations of ozone on the oxidation reaction was weak, due to the rapid pyrolysis; from groups 6 and 8, it can be seen that the presence of perchlorethylene could slightly increase TA selectivity, 4-CBA selectivity and PX conversion rate; from groups 7 and 8 , it can be seen that the presence of bromide can significantly increase the conversion of PX. Meanwhile, it could improve the selectivity of 
TA and reduce the selectivity of PT.

\section{CONCLUSIONS}

In this paper, the method for preparing TA adopted catalytic oxidation of PX in the liquid phase under the condition of low temperature and atmospheric pressure. The optimum conditions were as follows: cobalt acetate dosage $0.10 \mathrm{~mol} / \mathrm{mol} \mathrm{PX}$, acetic acid dosage $17 \mathrm{~mol} / \mathrm{mol} \mathrm{PX}$, reaction temperature $80^{\circ} \mathrm{C}$, reaction time $6 \mathrm{~h}$, ozone concentration $63.0 \mathrm{mg} / 1$, and gas flow rate $0.8 \mathrm{l} / \mathrm{min}$. In this case, $\mathrm{PX}$ conversion rate was $76 \%$ and selectivity was $84 \%$. If $0.545 \mathrm{mmol} \mathrm{KBr} / \mathrm{mol} \mathrm{PX}$ was introduced into the same system, the conversion of PX was up to $96 \%$ and the selectivity was $84 \%$; if ozone concentration continued to increase, the conversion of PX increased approximately linearly and the reaction selectivity remained unchanged.

Under the condition of low temperature of $80^{\circ} \mathrm{C}$, other conditions remained unchanged. When ozone or cobalt acetate was used alone, the conversion rate of PX was low. When ozone, cobalt acetate, and a small amount of bromide were used together, the conversion rate of PX was significantly increased, indicating that ozone, cobalt acetate, and bromide had obvious synergistic effects. However, with the increase in temperature, the decomposition rate of ozone was accelerated. At this time, ozone had little effect on the reaction while cobalt acetate and bromide were used simultaneously, the conversion rate of PX could be improved significantly.

\section{REFERENCES}

1. Kim DS, Shin YH, Lee YW (2015) Synthesis of terephthalic acid by catalytic partial oxidation of $p$-xylene in supercritical carbon dioxide. Chem Eng Comm 202, 78-84.

2. Tomás RAF, Bordado JCM, Gomes JFP (2013) p-Xylene oxidation to terephthalic acid: a literature review oriented toward process optimization and development. Chem Rev 113, 7421-69.

3. Wang Q, Li X, Wang L, Cheng Y, Xie G (2005) Kinetics of $p$-xylene liquid-phase catalytic oxidation to terephthalic acid. Ind Eng Chem Res 44, 261-6.

4. Partenheimer $\mathrm{W}$ (2014) The influence of $\mathrm{pH}$ in metal/bromide catalyzed homogeneous aerobic autoxidation. Part 2. Precipitation of metals by aromatic acids. Appl Catal A 481, 190-5.

5. Viola A, Cao G (1996) Rapid direct analysis of $p$-xylene oxidation products by reversed-phase highperformance liquid chromatography. $J$ Chromatogr Sci 34, 27-33.
6. Cao G, Servida A, Pisu M, Morbidelli M (1994) Kinetics of $p$-xylene liquid-phase catalytic oxidation. AIChE J 40, 1156-66.

7. Cao G, Pisu M, Morbidelli M (1994) A lumped kinetic model for liquid-phase catalytic oxidation of $p$-xylene to terephthalic acid. Chem Eng Sci 49, 5775-88.

8. Partenheimer W, Gipe RK (1993) Nature of the Co$\mathrm{Mn}-\mathrm{Br}$ catalyst in the methylaromatic compounds process: kinetic and thermodynamic studies. In: Oyama ST, Hightower JW (eds) Catalytic Selective Oxidation, ACS publications, DC, pp 81-8.

9. Sun W, Pan Y, Zhao L, Zhou X (2008) Simplified free-radical reaction kinetics for $p$-xylene oxidation to terephthalic acid. Chem Eng Tech 31, 1402-9.

10. Galstyan AG, Galstyan SG, Tyupalo NF (2010) Reaction of toluene with ozone in the liquid phase. Russ $J$ Appl Chem 83, 267-70.

11. Digruov NG, Dyakonov JA, Lebedev NN (1970) Kinetics of liquid-phase oxidation of $p$-xylene into terephthalic acid with a cobalt bromide catalyst. Izv Vyssh Uchebn Zaved Khim Khim Tekhnol 13, 407-12.

12. Partenheimer W (1995) Methodology and scope of metal/bromide autoxidation of hydrocarbons. Catal Today 23, 69-158. 